\title{
Loss of cell-adhesion molecule complexes in solid pseudopapillary tumor of pancreas
}

\author{
Wendell W Tang,6,*, Arwen A Stelter ${ }^{2, *}$, Samuel French ${ }^{3}$, Steven Shen ${ }^{4}$, Suimin Qiu ${ }^{1}$, \\ Rose Venegas $^{3}$, Julie Wen ${ }^{1}$, Hui-Qun Wang ${ }^{5}$ and Jingwu Xie ${ }^{2}$ \\ ${ }^{1}$ Department of Pathology, University of Texas Medical Branch at Galveston, Galveston, TX, USA; \\ ${ }^{2}$ Department of Pharmacology \& Toxicology, University of Texas Medical Branch at Galveston, Galveston, \\ TX, USA; ${ }^{3}$ Department of Pathology, Harbor-UCLA Medical Center, Torrance, CA, USA; ${ }^{4}$ Department of \\ Pathology, Methodist Hospital, Houston, TX, USA; ${ }^{5}$ Department of Biochemistry and Molecular Biology, \\ University of Texas Medical Branch at Galveston, Galveston, TX, USA and ${ }^{6}$ Department of Pathology and \\ Laboratory Medicine, Ochsner Clinic Foundation, New Orleans, LA, USA
}

\begin{abstract}
Solid pseudopapillary tumor of pancreas (SPT) is a rare neoplasm that occurs most often in young females with the two distinct features, the 'solid-cystic' gross appearance, and the 'solid-pseudopapillary' microscopic pattern. It has been reported that almost all SPT tumors contain a mutation in the $\beta$-catenin gene; however, the histogenetic origin of this tumor remains largely a mystery. E-cadherin is a cell adhesion molecule that links to catenins to form cell adhesion junctions, which is associated with the cytoskeleton formation. In this study, we examined the expression of E-cadherin and $\beta$-catenin from SPT in an attempt to determine the molecular basis for the unusual morphology of this tumor. Nine cases of SPT were retrieved from Surgical Pathologic Archives of three institutions, including one male and eight females. H\&E slides of each case were reviewed to confirm the diagnosis. The $\beta$-catenin gene was sequenced in one case. E-cadherin and $\beta$-catenin immunostains, were performed on all nine cases. Sequencing analysis on one case showed a point mutation of the $\beta$-catenin gene, confirming previous findings that almost all SPT tumors contain mutation in the $\beta$-catenin gene. Immunostains showed that, in both solid and pseudopapillary areas, all the tumor cells lost expression of E-cadherin, and $\beta$ catenin nuclear expression was observed in all cases. Our findings suggest that loss of cytoplasmic $\beta$-catenin protein in the cell adhesion complex due to $\beta$-catenin gene mutation, results in instability of the complex, loss of E-cadherin in cell membrane, and eventually dissociation of the tumor cells to form the pseudopapillary pattern. Modern Pathology (2007) 20, 509-513. doi:10.1038/modpathol.3800764; published online 2 March 2007
\end{abstract}

Keywords: $\beta$-catenin; E-cadherin; GSK-3- $\beta$; solid pseudo-papillary tumor of pancreas

Solid pseudo-papillary tumor of the pancreas (SPT) is a rare tumor found predominantly in young females. As it was first described by Franz, ${ }^{1}$ numerous names have been suggested for this tumor, including Frantz's tumor; solid and papillary tumor; papillary cystic tumor; solid, cystic and papillary epithelial neoplasm; solid-cystic tumor; benign or malignant papillary tumor of the pancreas; papillary epithelial neoplasm of pancreas in a child and adenocarcinoma of the pancreas in childhood. ${ }^{1-3}$ These various names reflect the important features of this tumor, the 'solid-cystic' gross appearance and

Correspondence: Dr WW Tang, MD, PhD, Department of Pathology and Laboratory Medicine, Ochsner Clinic Foundation, 1514 Jefferson Highway, New Orleans, LA 70121, USA.

E-mails: wtang@ochsner.org or jinxie@utmb.edu

* These authors contributed equally to this work.

Received 13 November 2006; revised 09 January 2007; accepted 18 January 2007; published online 2 March 2007 the 'solid-pseudopapillary' histopathological pattern. Microscopically, the tumor cells in 'solid' areas are uniform, arranged in sheets and cords around fibrovascular septa; whereas those in 'pseudopapillary' areas show degenerative changes in the cells away from the vasculature. ${ }^{4-8}$ Despite its characteristic microscopic appearance and recent studies of this type of tumor for molecular changes, ${ }^{9}$ the immunophenotype of markers is not specific and does not define a line of differentiation corresponding to any normal pancreatic cell type.

The pathogenesis of such striking microscopic patterns has been studied extensively. Almost all SPTs harbor mutations in the $\beta$-catenin gene. ${ }^{10,11}$ Diffuse cytoplasmic and nuclear localization for $\beta$-catenin is found in this type of tumor. The Wnt signaling pathway, in which $\beta$-catenin protein functions as a downstream transcriptional co-activator, is thought to play a major role in tumorigenesis of SPT. $\beta$-Catenin protein also functions as a 
submembranous component of cell adhesion. The cytoplasmic tail of E-cadherin molecule is linked to the cytoskeleton through $\beta$-catenin and other small proteins. ${ }^{12,13}$ E-cadherin is a transmembrane protein that is present as a parallel dimer at the adhesion junction. The extracellular portion is involved in $\mathrm{Ca}^{2+}$-dependent, homotypic interactions with Ecadherin molecules on the surface of adjacent cells. The sequential binding of the catenin proteins ( $\beta$-cat and $\alpha$-cat) to the cytoplasmic tail of cadherin physically bridges the cadherin dimer with the actin cytoskeleton and actin-binding proteins. p120 catenin binds to the juxtamembrane region of the cytoplasmic tail of E-cadherin. The ability of the catenin proteins to interact with microtubule-plusend-binding proteins might potentially link the adhesion junction to the microtubule network.

In this study, we studied the expression of E-cadherin and $\beta$-catenin proteins in nine cases of SPTs to examine, whether cell adhesion is altered in this type of tumor.

\section{Materials and methods}

\section{Patients and Tissues}

Paraffin blocks from nine cases of SPT specimens were obtained from Surgical Pathology Archives of the University of Texas Medical Branch (Galveston, TX, USA), Harbor-UCLA Medical Center (Torrance, CA, USA), and Methodist Hospital (Houston, TX, USA). Sections were stained with hematoxylin and eosin to confirm the presence of SPT on the paraffin blocks subjected to the study. These cases are listed in Table 1.

The patients' characteristics are as follows: median age 38 (range 10-49 years), both male and female, mean tumor size $5.9 \mathrm{~cm}$ (range $3.2-12.8 \mathrm{~cm}$ ). The location of tumor in pancreas: three at head, one at body, and five at tail. Eight of the nine tumors are confined within pancreas. No lymph node involvement in any of the tumors.

\section{Immunohistochemistry}

Immunohistochemical stains with E-cadherin (Zymed, San Francisco, CA, USA; 1:200) and $\beta$-catenin (Dako, Glostrup, Denmark; 1:100) were performed in these nine cases. Count staining was performed using hematoxylin.

\section{Genetic Analysis}

SPT and surrounding normal pancreatic glandular tissue were first deparaffinized; DNA was then isolated by standard technique. ${ }^{14} \beta$-Catenin-specific primers were used to amplify the $\beta$-catenin gene exon II. Primer sequences: forward 5'-AGC TGA TTT GAT GGA GTT GG-3'; reverse 5'-ACC AGC TAC TTG TTC TTG AG-3'. The PCR products were sequenced and compared with wild-type $\beta$-catenin gene in GenBank (AY081165).

\section{Results}

As shown in Figure 1, hematoxylin and eosin stained slides of all nine tumors show similar classic microscopic features of SPT: solid and pseudopapillary tumor pattern (Figure 1). The solid area was surrounded by pseudo-papillary area.

To test whether cell adhesion is altered in SPT, we examined expression of E-cadherin and $\beta$-catenin by immunohistochemistry. As shown in Figure 2, all the tumors, regardless of 'solid' or 'pseudopapillary' regions, were negative for E-cadherin staining; whereas the surrounding glandular cells are positive. In contrast, nuclear localization of $\beta$-catenin is detected in both 'solid' and 'pseudo-papillary' regions (Figure 3). Expression of these cell adhesion molecules is altered in SPT, which can be used to differentiate tumor tissues from the surrounding normal pancreas.

To test whether gene mutation of $\beta$-catenin is responsible for nuclear localization of the protein, we examined the exon III of the $\beta$-catenin gene from Case 2 SPT tumor cells. Sequencing the genomic DNAs extracted from deparaffinized tissue revealed a single base pair change (S33C), which is located in a GSK-3- $\beta$ phosphorylation site (Figure 4 ). ${ }^{15-17}$ This finding is consistent with previous literature reports that $\beta$-catenin mutations occur commonly in this type of tumor.

These results indicate that loss of adhesion molecule complexes is an important feature of

Table 1 The patient characteristics of nine SPT cases

\begin{tabular}{|c|c|c|c|c|c|}
\hline Case & Age & Sex & Pancreatic site & Tumor size $(\mathrm{cm})$ & Tumor stage \\
\hline 1 & 24 & Female & Body & 5.0 & IB \\
\hline 2 & 43 & Female & Head & 6.1 & IB \\
\hline 3 & 41 & Female & Tail & 3.4 & IB \\
\hline 4 & 10 & Female & Head & 6.5 & IB \\
\hline 5 & 31 & Female & Head & 6.5 & IB \\
\hline 6 & 38 & Male & Tail & 7.0 & IB \\
\hline 7 & 26 & Female & Tail & 3.0 & IB \\
\hline 8 & 49 & Female & Tail & 12.8 & IB \\
\hline 9 & 49 & Female & Tail & 3.2 & IIA \\
\hline
\end{tabular}



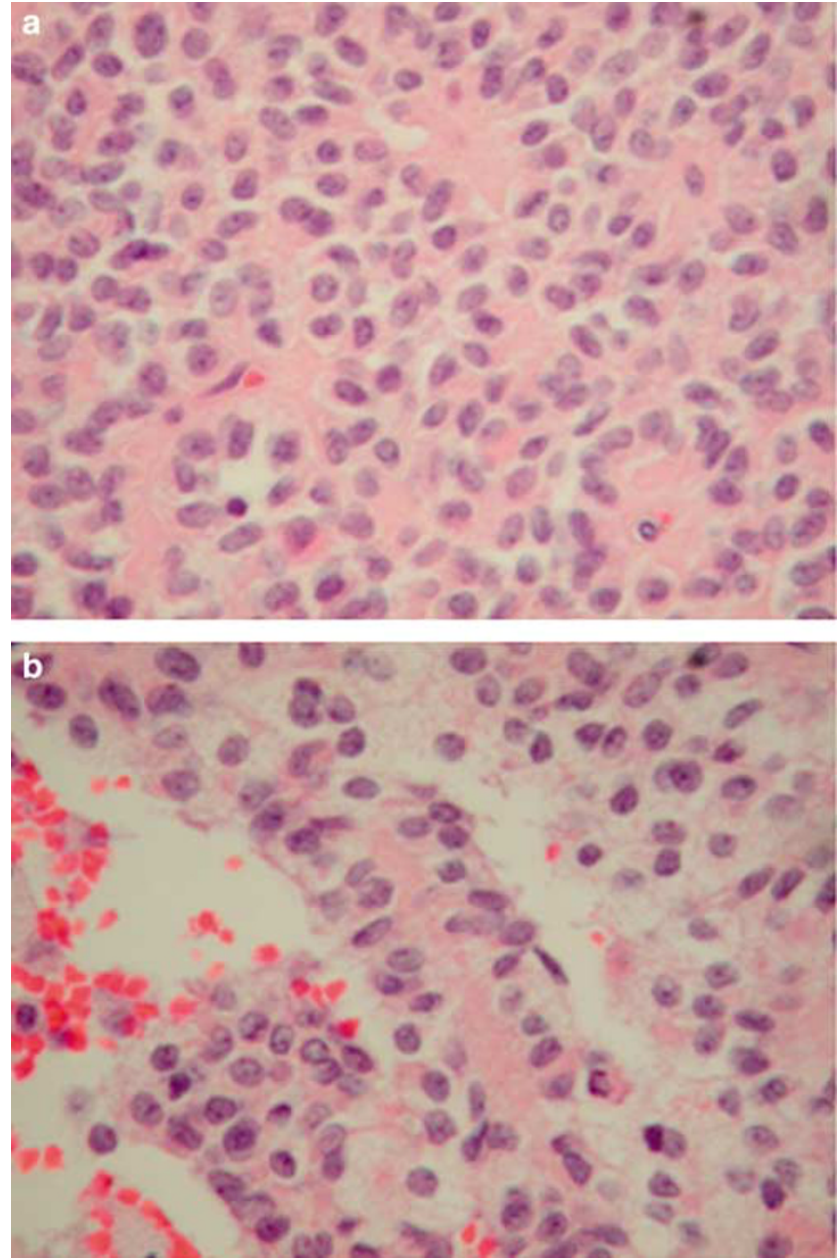

Figure 1 Hematoxylin and eosin staining of specimens from solid pseudopapillary tumor of pancreas $(\times 400)$. (a) Case 1 solid area; (b) case 1 pseudopapillary area.

SPT, and may be useful for future clinical diagnosis of this tumor type.

\section{Discussion}

Since it was first described in 1959, the origin and pathogenesis of SPT have been controversial. Mutations of the $\beta$-catenin gene have been identified in most cases of SPTs. ${ }^{10}$ The mutations are mostly at or around the GSK-3- $\beta$ phosphorylation sites. It has been postulated that these somatic mutations would interfere with normal phosphorylation by GSK-3- $\beta$ and the subsequent ubiquitin-mediated degradation of the $\beta$-catenin protein. This is consistent with the fact that strong nuclear and cytoplasmic accumulation of $\beta$-catenin protein is present in nearly all SPTs, and that cyclin D1, a downstream transcriptional target of the nuclear $\beta$-catenin-Tcf/Lef complex, is overexpressed in SPTs. In our study, the $\beta$ catenin gene from SPT contains a somatic mutation, which changes from serine to cysteine. This S33C
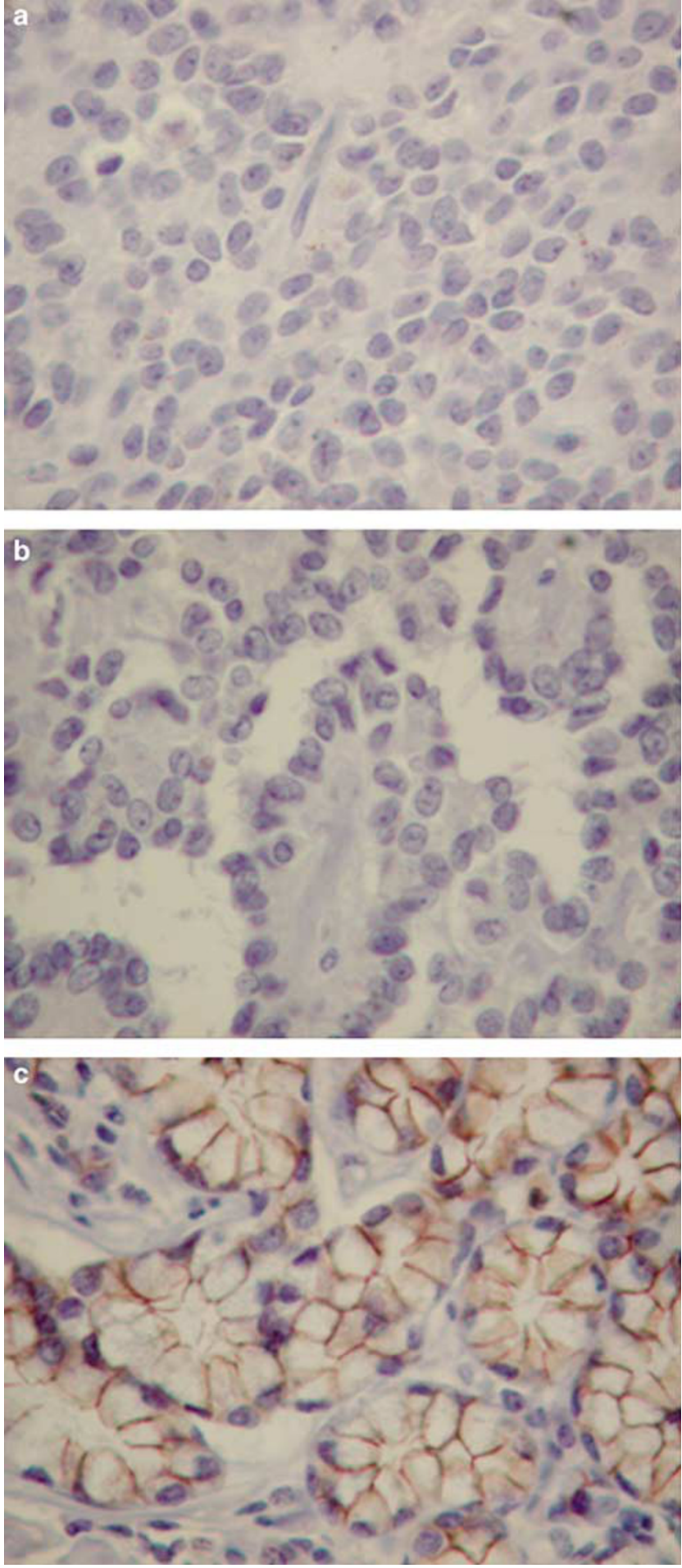

Figure 2 Immunohistochemistry detection of E-cadherin in SPT specimens $(\times 400)$; (a) case 1 solid area; (b) case 1 pseudopapillary area; (c) case 1 normal duodenal gland. Positive staining is in red. Count staining was performed using hematoxylin.

mutation has been identified in $\beta$-catenin genes of various tumors ${ }^{15,18-20}$ and this serine has been shown to be mutated in other SPTs. ${ }^{10}$ On the basis of these findings, it is suggested that the Wnt 
signaling is associated with $\beta$-catenin mutations and may play an important role in tumorigenesis of SPT. ${ }^{10}$ However, this hypothesis fails to explain the
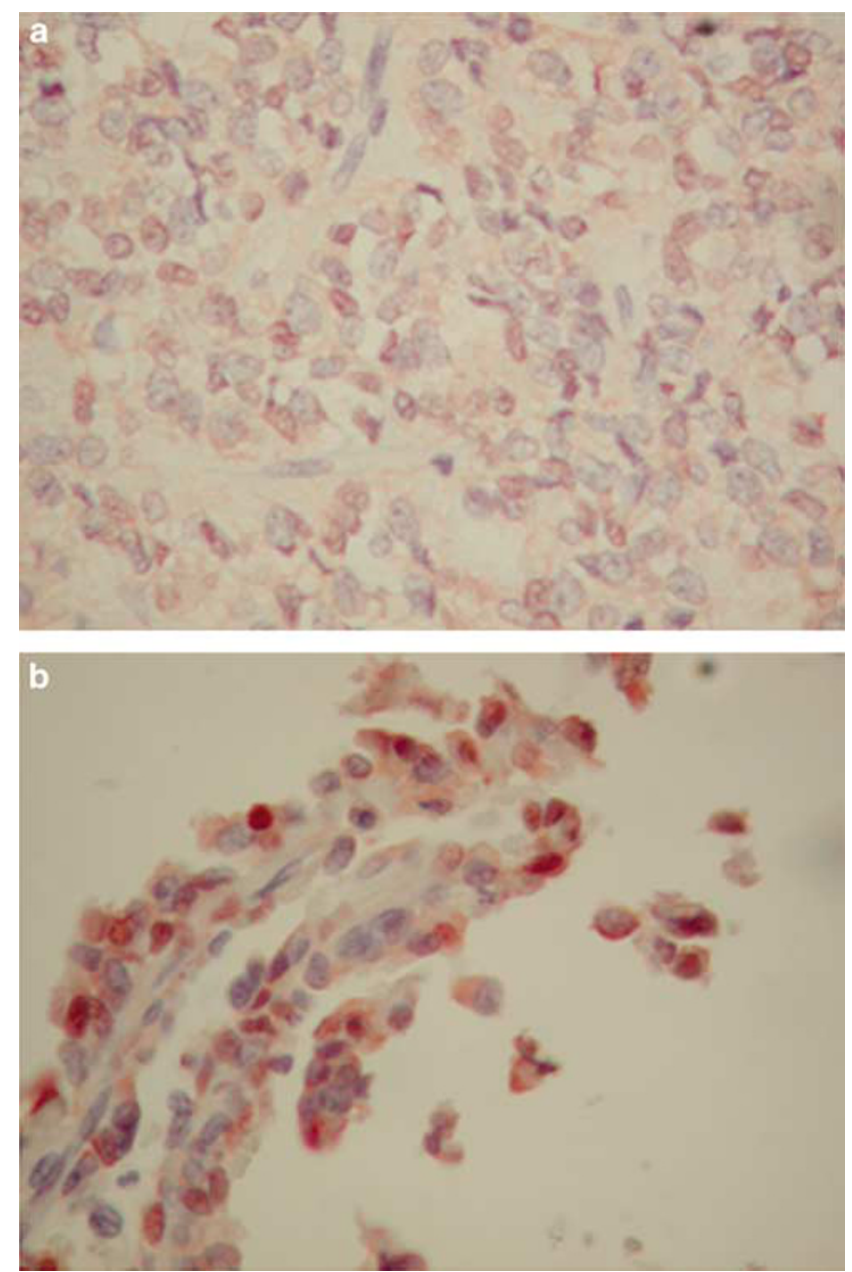

Figure 3 Immunohistochemistry detection of $\beta$-catenin in SPT specimens $(\times 400)$; (a) case 1 solid area; (b) case 1 pseudopapillary area. Positive staining was in red and count staining was performed using hematoxylin. characteristic microscopic 'solid' and 'pseudopapillary' features in SPT.

It has been well known that $\beta$-catenin protein is an important linking molecule between E-cadherin and the cytoskeleton. Our immunohistochemical staining of E-cadherin and $\beta$-catenin suggest that nuclear localization of $\beta$-catenin as well as E-cadherin loss are important changes in this type of tumor. Although it is known that $\beta$-catenin mutation can cause disorganization of E-cadherin, silencing of E-cadherin by a variety of factors has been reported in several types of tumors. On the basis of these data, we propose that disruption of adhesion junction is the major feature for SPT. Whereas

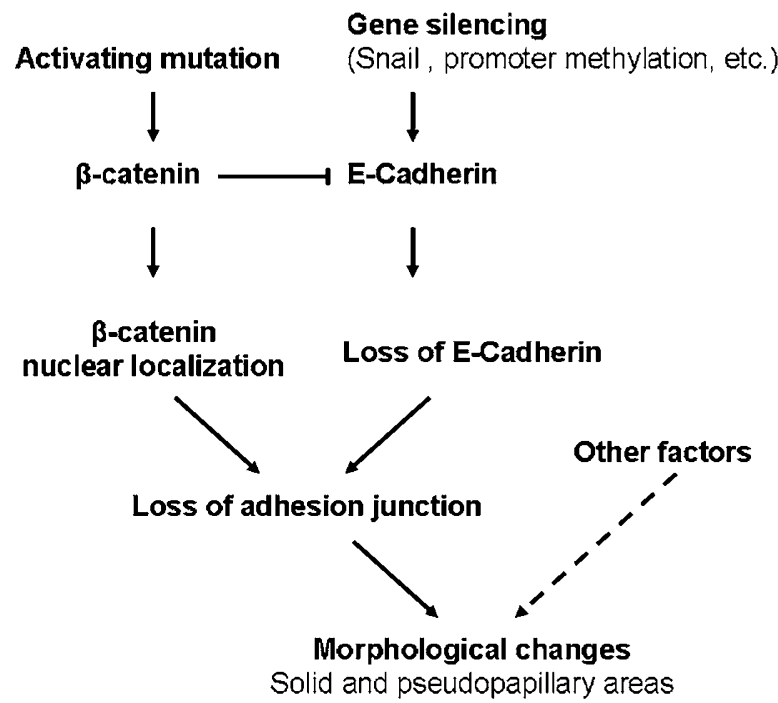

Figure 5 A model for development of SPT. Loss of adhesion junction is an important feature of SPT through silencing of E-cadherin expression and nuclear translocation of $\beta$-catenin after activating mutations. Mutation of $\beta$-catenin can also disrupt E-cadherin localization. In the absence of adhesion junction, other factors can promote morphological changes of SPT to be either 'solid' or 'pseudopapillary'.

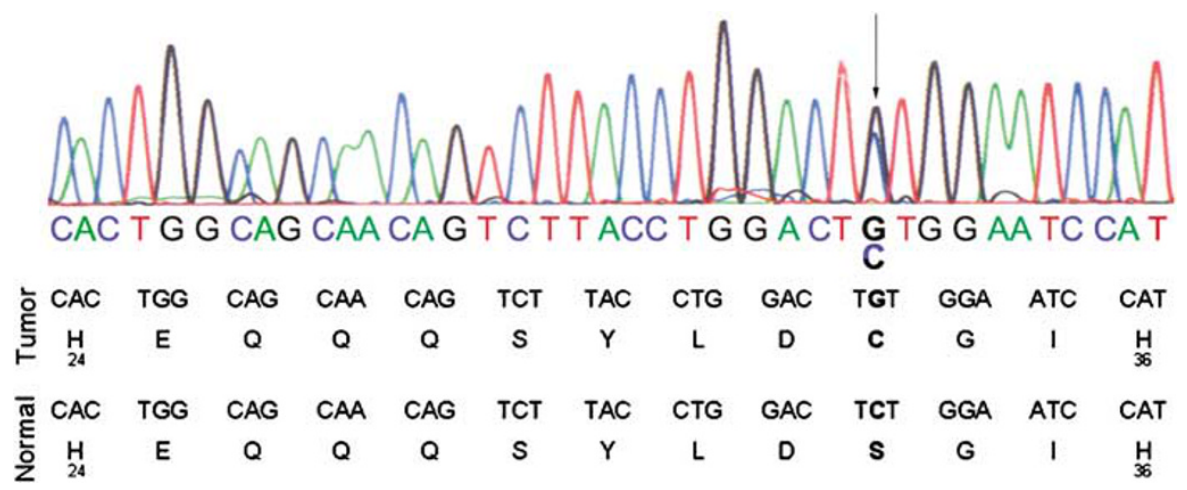

Figure 4 Mutation analysis of $\beta$-catenin in the tumor-S33C mutation. Genomic DNAs from paraffin-embedded tissues were purified using a procedure reported previously, ${ }^{14}$ and the exon III genomic DNA of the $\beta$-catenin was amplified by PCR as reported primers (21). Alteration of $\beta$-catenin was detected by direct sequencing of the PCR product in our core facility. The mutation of $\mathrm{C}$ to $\mathrm{G}$ was indicated by an arrow, which results in a missense mutation of Ser35 to Cys35 as predicted from GenBank AY081165 and GenPept AAL89457. Only the sequence encoding amino acids $24-36$ was shown. The mutation was confirmed by two independent experiments. 
nuclear translocation is caused by $\beta$-catenin mutation, loss of E-cadherin expression can result from promoter silencing, overexpression of transcription repressors such as Snail. As a result of adhesion junction disruption, the pseudopapillary portion of the tumor is formed with help of other factors, such as mechanic stress. Figure 5 shows our proposed model for morphological development of SPT.

In conclusion, our results suggest that loss of adhesion junction is a unique microscopic feature distinguishing the SPT tumor from the normal pancreas. Our findings suggest that loss of cytoplasmic $\beta$-catenin protein in the cell adhesion complex due to $\beta$-catenin gene mutation results in instability of the complex, loss of E-cadherin in cell membrane, and eventually dissociation of the tumor cells to form the pseudopapillary pattern.

\section{Acknowledgement}

Grant numbers and sources of support: NCI R0194160 (Xie, J), Sealy Center for Cancer Cell Biology Predoctoral fellowship (Stelter, AA) and NASA scholarship (Stelter, AA).

\section{References}

1 Frantz VK. Tumors of the pancreas. In: Atlas of Tumor Pathology, Vol. 7. Armed Forces Institute of Pathology: Washington, DC, 1959, pp 32-33.

2 Kloppel G, Luttges J, Klimstra DS, et al. Solidpseudopapillary Neoplasm. IARC Press: Lyon, France, 2000, pp 473-480.

3 Solcia E, Capella C, Kloppel G. Tumors of the pancreas. In: Atlas of Tumor Pathology, 3rd series. Armed Forces Institute of Pathology: Washington, DC, 1997, pp 120-130.

4 Klimstra DS, Wenig BM, Heffess CS. Solid-pseudopapillary tumor of the pancreas: a typically cystic carcinoma of low malignant potential. Semin Diagn Pathol 2000;17:66-80.

5 Papavramidis T, Papavramidis S. Solid pseudopapillary tumors of the pancreas: review of 718 patients reported in English literature. J Am Coll Surg 2005;200:965-972.

6 Pettinato G, Manivel JC, Ravetto C, et al. Papillary cystic tumor of the pancreas. A clinicopathologic study of 20 cases with cytologic, immunohistochemical, ultrastructural, and flow cytometric observations, and a review of the literature. Am J Clin Pathol 1992;98:478-488.

7 Yamaguchi K, Tanaka M. Radiologic imagings of cystic neoplasms of the pancreas. Pancreatology 2001;1: 633-636.

8 Kosmahl M, Seada LS, Janig U, et al. Solid-pseudopapillary tumor of the pancreas: its origin revisited. Virchows Arch 2000;436:473-480.

9 Tiemann K, Kosmahl M, Ohlendorf J, et al. Solid pseudopapillary neoplasms of the pancreas are associated with FLI-1 expression, but not with EWS/FLI-1 translocation. Mod Pathol 2006;19:1409-1413.

10 Abraham SC, Klimstra DS, Wilentz RE, et al. Solidpseudopapillary tumors of the pancreas are genetically distinct from pancreatic ductal adenocarcinomas and almost always harbor $\beta$-catenin mutations. Am J Pathol 2002;160:1361-1369.

11 Tanaka Y, Kato K, Notohara K, et al. Frequent $\beta$-catenin mutation and cytoplasmic/nuclear accumulation in pancreatic solid-pseudopapillary neoplasm. Cancer Res 2001;61:8401-8404.

12 Hajra KM, Chen DY, Fearon ER. The SLUG zinc-finger protein represses E-cadherin in breast cancer. Cancer Res 2002;62:1613-1618.

13 Aberle H, Schwartz H, Kemler R. Cadherin-catenin complex: protein interactions and their implications for cadherin function. J Cell Biochem 1996;61: 514-523.

14 Sheng $\mathrm{T}$, Li C, Zhang X, et al. Activation of the hedgehog pathway in advanced prostate cancer. Mol Cancer 2004;3:29.

15 Chan EF, Gat U, McNiff JM, et al. A common human skin tumour is caused by activating mutations in $\beta$-catenin. Nat Genet 1999;21:410-413.

16 Orford K, Crockett C, Jensen JP, et al. Serine phosphorylation-regulated ubiquitination and degradation of $\beta$-catenin. J Biol Chem 1997;272:24735-24738.

17 Liu C, Li Y, Semenov M, et al. Control of $\beta$-catenin phosphorylation/degradation by a dual-kinase mechanism. Cell 2002;108:837-847.

18 Mirabelli-Primdahl L, Gryfe R, Kim H, et al. $\beta$-catenin mutations are specific for colorectal carcinomas with microsatellite instability but occur in endometrial carcinomas irrespective of mutator pathway. Cancer Res 1999;59:3346-3351.

19 Wright $\mathrm{K}$, Wilson $\mathrm{P}$, Morland $\mathrm{S}$, et al. $\beta$-catenin mutation and expression analysis in ovarian cancer: exon 3 mutations and nuclear translocation in $16 \%$ of endometrioid tumours. Int J Cancer 1999;82:625-629.

20 Gamallo C, Palacios J, Moreno G, et al. $\beta$-catenin expression pattern in stage I and II ovarian carcinomas: relationship with $\beta$-catenin gene mutations, clinicopathological features, and clinical outcome. Am J Pathol 1999;155:527-536. 